\title{
Engineering soft nanostructured functional materials via orthogonal chemistry
}

\author{
Daniel Gromadzki
}

Published online: 15 August 2010

(C) The Author(s) 2010. This article is published with open access at Springerlink.com

\begin{abstract}
Nanostructured amphiphilic block copolymers, graft copolymers, polymeric thermally responsive molecular brushes and polymer stars are only few examples of macromolecular architectures accessible either via controlled/living radical polymerization (CLRP) techniques or the combination of CLRP mechanisms with efficient post-polymerization routes including click chemistry. Precise control over the composition, molecular weight and functionalities is a prerequisite for soft polymeric materials to selforganize into ordered morphologies. This contribution describes novel orthogonal chemical routes for the synthesis of macromolecular architectures and selfassembly of functional soft polymeric materials. Emerging potential applications of well-defined block and graft copolymers are outlined as well.
\end{abstract}

Keywords Polymerization - Self-assembly · Nanostructured functional polymers

D. Gromadzki $(\square)$

Fundamentals of Advanced Materials Group,

Faculty of Aerospace Engineering,

Delft University of Technology,

Kluyverweg 1, 2629 HS Delft, The Netherlands

e-mail: D.Gromadzki@tudelft.nl

\section{Introduction}

Soft nanostructured polymeric materials can be generated via bottom up and top down approaches relying either on direct chemical synthesis and molecular selfassembly into desired conformation and morphology or externally controlled routes for achieving selfassembly (e.g. nanolithography), respectively (Xia and Whitesides 1998). Currently more sophisticated polymeric materials including block copolymers, brushes, stars, tadpole-shaped or hyperbranched copolymers with unprecedented control of molecular and architectural parameters are readily accessible thanks to impressive breakthrough in development of synthetic methodologies, namely controlled/living radical polymerization-CLRP- (Braunecker and Matyjaszewski 2007) and click chemistry (Kolb et al. 2001).

Block copolymers are fascinating macromolecules exhibiting ability to self-organize into ordered morphologies at the nanoscale via the process of microphase separation (Ruzette and Leibler 2005). Figure 1 shows some of block copolymer architectures accessible by macromolecular engineering.

Spontaneous self-assembly of diblock copolymers leads to formation of long-range ordered mesophases typically body-centered arrays of spheres, cylinders, bicontinuous-double-diamond and lamellae with a size ranging from few to hundred nanometers, depending upon composition $(\Phi)$ as shown in Fig. 2. The phase behavior of block copolymers is governed by 


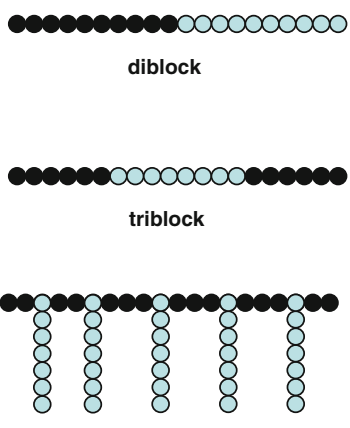

graft copolymer

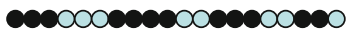

random multiblock

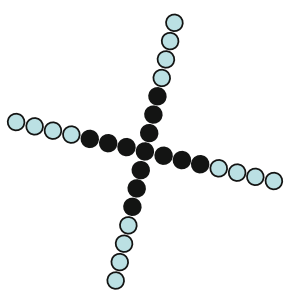

four arm starblock

Fig. 1 Example of block copolymer architectures accessible via CLRP

incompatibility of building segments given by the product of the Flory-Huggins interaction parameter $(\chi)$ and degree of polymerization $(N)$. In addition, the self-organization of block copolymers is influenced by processing parameters (casting conditions, solvent, temperature etc.). More importantly, the intrinsic molecular parameters like sequence of monomeric units (random, gradient) and molecular weight distribution (polydispersity) have a profound effect on block copolymer self-assembly. The latter parameter is of particular importance because all block copolymers prepared by CLRP schemes exhibit a certain

molecular weight distribution due to the fact that termination events during the course of CLRP are not completely eliminated. On the other hand, polydispersity resulting from imperfections inherent to particular CLRP routes can be beneficial in designing selfassembled nanostructures (order-order phase transitions and size of microphase separated domains).

Therefore, better understanding of the kinetics of the CLRP processes will allow controlling selfassembly in block copolymers. Notwithstanding the fact that the effect of polydispersity on molecular disorder has been recognized long ago, it was until recently that the first experimental results from CLRP-block copolymers could emerge (Lynd et al. 2008).

\section{Working principle}

Synthesis of block and graft copolymers with defined architecture can be achieved from almost any radically polymerizable monomer under facile conditions of CLRP in bulk, solution and in dispersed media. In addition, nearly $50 \%$ of all commercial synthetic polymers are prepared using radical chemistry which makes CLRP attractive for industrial applications. Among various CLRP systems introduced in the past
Fig. 2 Phase diagram for diblock copolymers representing typical mesophases: face centered cubic $(F C C)$, body centered cubic (BCC), hexagonal (HEX), bicontinuous gyroid $(G Y R)$ and lamellar (LAM) phase. Reprinted with permission fromhttp:// www.physics.nyu.edu/ pine/research/ nanocopoly.html

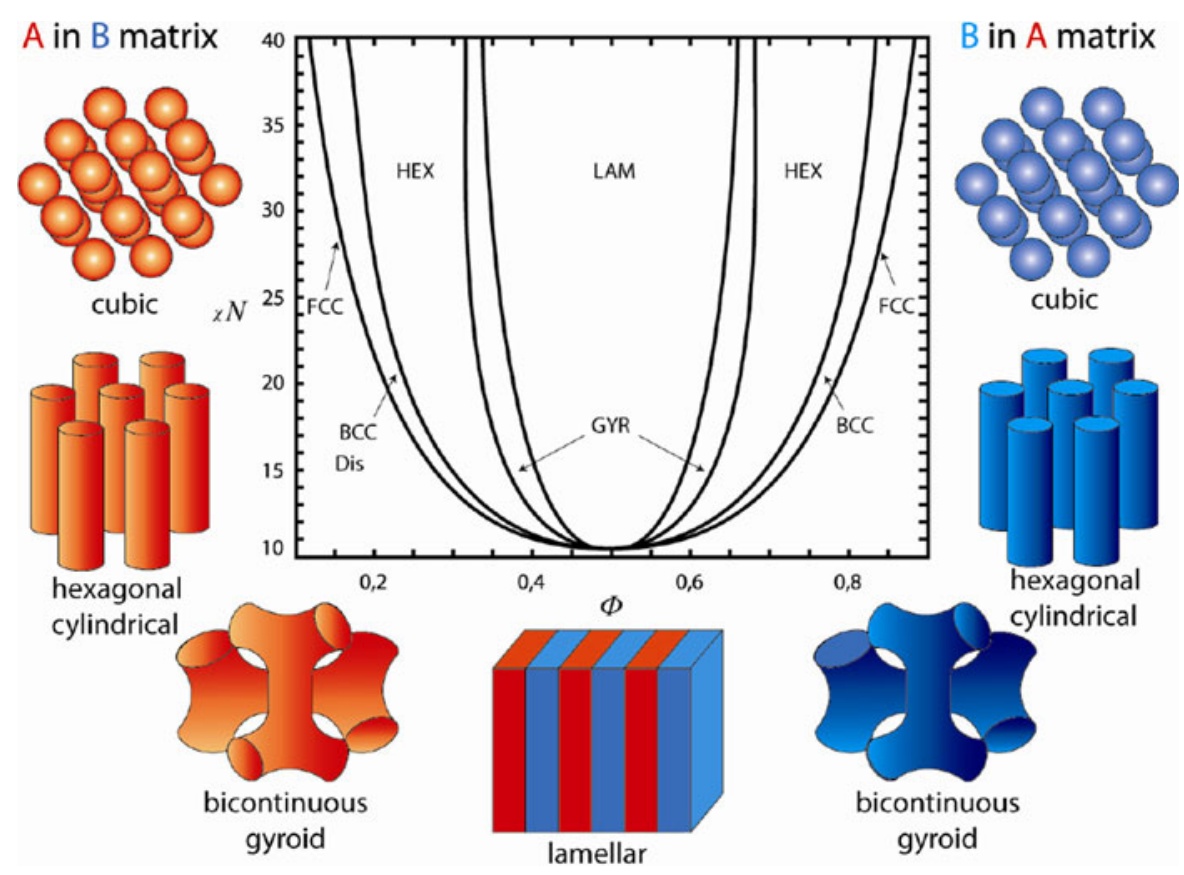




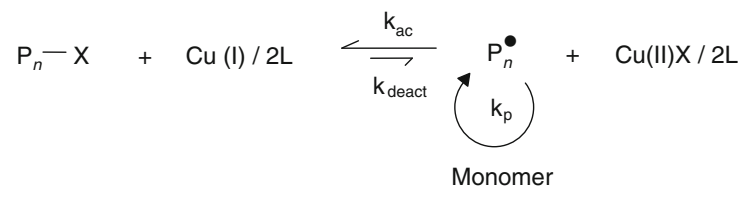

Fig. 3 Mechanism of atom transfer radical polymerization

decade nitroxide-mediated radical polymerization (NMP), atom transfer radical polymerization (ATRP) and reversible-addition fragmentation chain transfer polymerization (RAFT) are the most commonly used techniques (Braunecker and Matyjaszewski 2007). The key feature of all CLRP processes is based on establishment of a dynamic equilibrium between propagating radicals and various dormant species. For instance, in ATRP polymerization a copper (I) complex, $\mathrm{CuX} / 2 \mathrm{~L}\left(\mathrm{X}=\mathrm{Cl}\right.$ or $\mathrm{Br}$, and $\mathrm{L}=2,2^{\prime}$ bipyridine [bipy] or a 4,4'-disubstituted-2,2'-bipyridine) activates reversibly the dormant polymer chains via a halogen atom transfer reaction (Fig. 3). It is the dynamic equilibrium between growing radicals and dormant species which is responsible for controlled behavior of ATRP and a synthesis of well-defined macromolecules with a degree of polymerization set by the ratio of the concentrations of converted monomer $[\mathrm{M}]$ to the introduced initiator $[\mathrm{I}]_{\mathrm{o}}$, $\left(D P=\Delta[\mathrm{M}] /[\mathrm{I}]_{\mathrm{o}}\right)$.

The discovery of CLRP techniques in the past decade has set tremendous impact on contemporary polymer science. Each technique has its advantages and limitations. For instance, until recently NMP was applicable mostly for the synthesis of styrene and styrene-like derivatives. ATRP and RAFT are able to polymerize wider range of monomers although direct polymerization of acidic monomers to afford well- defined polyelectrolytes or block copolymers containing acidic segments is very difficult since most CLRP mediating agents are sensitive to acidic conditions. This can be circumvented by selective post-functionalization of one block of a copolymer prepared by living polymerization, for example, using efficient azidenitrile click chemistry (Gromadzki et al. 2008a, b).

Very often synthesis of a desired architecture cannot be accomplished using a single mechanism but the combination of various CLRP mechanisms must be attempted. This is especially true for the preparation of comb-like copolymers. Figure 4 illustrates synthesis of comb-like copolymers with various grafting density via the "grafting from" process. The first step involves preparation of polymeric backbone (macroinitiator) by copolymerization of monomers at a given polymerization feed in order to adjust concentration of initiating sites (black dots) while the second step is actually the grafting process of a functional monomer building side chains. Since both syntheses of macroinitiatior and side chains have been conducted under CLRP conditions, the resulting well-defined comb polymer is an excellent model system to gain insight into fundamental questions in soft matter in general and in polymer physics in particular, namely the correlation between molecular structure, conformation and macroscopic properties.

One of the main goals of the Marie Curie Research and Training Network Self-Organization under Confinement (MCRTN-SOCON) network was to shed light on the properties of comb-like copolymers in solution, bulk and at surfaces (Claesson et al. 2010). A range of diverse comb copolymers have been prepared either by conventional radical polymerization involving the macromonomer route or by using

Fig. 4 Synthesis of comblike copolymers via controlled/living radical polymerization

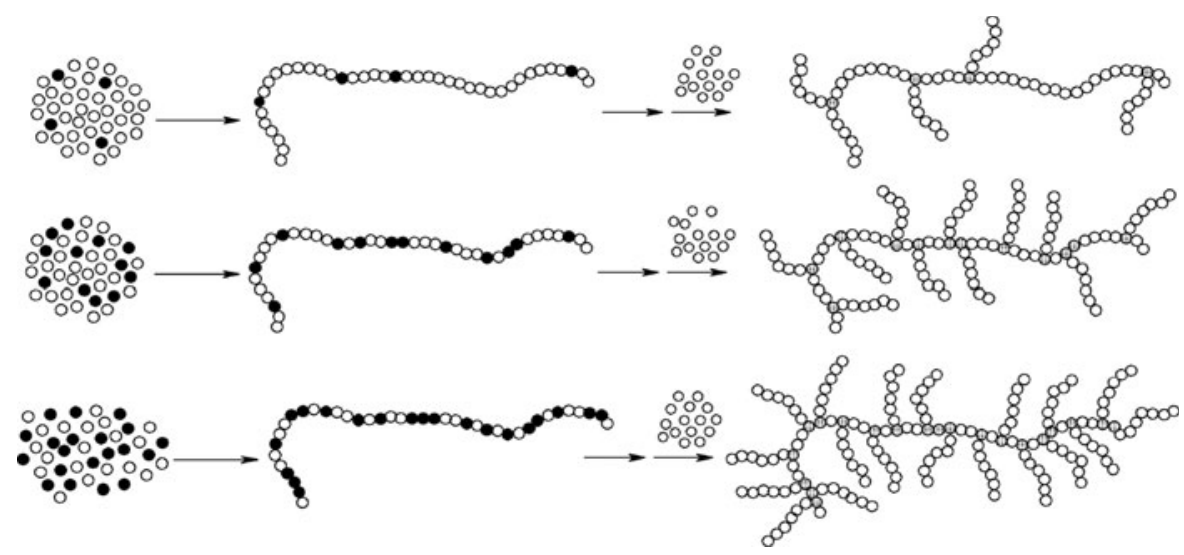


various novel synthetic pathways, i.e. "grafting from" ATRP (Krivorotova et al. 2010a, b, "grafting through" RAFT (Krivorotova et al. 2010a, b), NMP combined with "grafting from" iniferter or "grafting onto" strategy Gromadzki et al. (2008a, b, 2010) and azide-alkyne click chemistry (Kulbokaite et al. 2009). Most of the polymers synthesized exhibit a high level of tunability because they are responsive to changes in temperature, $\mathrm{pH}$, salt and humidity, electric field enabling tailoring of the properties or solution behavior to a desired range.

\section{Application fields}

Block and graft copolymers are of immense technological importance. Many commercial applications of block copolymers are already known, such as thermoplastic elastomers which can be used as adhesives, sealants, breathable cloths, gels and coatings etc. (Holden et al. 2004).

Photonic gels and high-density data storage media are another field of block copolymers application as active components of display or telecommunication devices for controlling and processing light (Kang et al. 2007). The position of a stop band has been adjusted either by changing the refractive index or the domain spacing of the crystal structure by addition of homopolymer or using external stimuli (swelling, salt, electric field). However, the microdomain spacing in ordered block copolymers nanostructure can be tuned simply by changing polydispersity (Lynd et al. 2008). This additional tool inherent to CLRP has not yet been addressed in the design of photonic gels and other soft materials but it is likely to attract attention of researchers in the near future.

Amphiphilic block copolymers composed of hydrophobic and hydrophilic segments are known to form micelles in aqueous milieu with hydrophobic core and hydrophilic shell as represented schematically in Fig. 5. Such assemblies with mesoscopic size range have witnessed much attention in pharmaceutical and biomedical field as carrier systems in targeted drug delivery (Kataoka et al. 1993). Size and surface properties of polymeric micelles are crucial in achieving high efficiency in drug delivery. Again, robust orthogonal chemical strategies will be central to development of novel colloidal drug delivery carriers (Iha et al. 2009). For instance, most

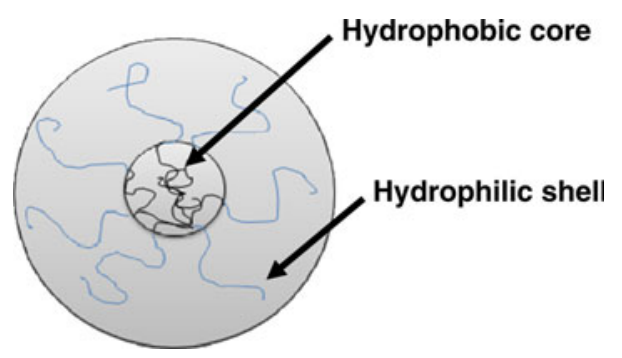

Fig. 5 Spherical multimolecular diblock copolymer micelle

of the polymers prepared by ATRP are terminated with halogen end-groups which after appropriate transformations can be used for conjugation of active molecules via click chemistry. This allows fine-tuning of the material properties both at molecular level and on the self-assembled nanostructure surface.

Branched polymers are an industrially relevant class of polymers and find numerous applications as compatibilizers, lubricants, viscosity and impact modifiers. Stimuli-responsive densely grafted brushes (macromolecular cylindrical brushes) synthesized within the SOCON network hold great promise for such divers applications like biomedicine (smart drug delivery carrier), biotechnology (purification of proteins), electronic (as medium in lithium-ion battery) and last but not least in surface technology (lubrication and anti-fouling modifiers).

\section{Training of young researchers}

Dr. Daniel Gromadzki pursued his $\mathrm{PhD}$ in the field of macromolecular chemistry within the Institute of Macromolecular Chemistry of the Czech Academy of Sciences and Charles University in Prague, Czech Republic. His first Marie Curie Fellowship under Marie Curie Initial Research and Training Site at the Institute of Macromolecular Chemistry in Prague gave him the opportunity to engage into an interdisciplinary and international research team working both on synthesis and structural characterization of nanostructured block copolymers intended for application as membranes for fuel cells. Interaction with synthetic chemists and polymer physicists allowed him to acquire skills in design of macromolecular architectures by modern methods of polymerization and to work with unique techniques to characterize structural properties of polymers. 
Table 1 Mobility of Marie Curie fellow Dr. Gromadzki

\begin{tabular}{|c|c|c|}
\hline Year & Institute & Topics and skills acquired \\
\hline 2001 & BASF AG, Ludwigshafen, Germany & Water-borne coatings, dispersions, foams \\
\hline 2001 & $\begin{array}{l}\text { Department of Environmental Engineering, Technical } \\
\text { University of Szczecin, Poland }\end{array}$ & Catalysis \\
\hline 2002 & $\begin{array}{l}\text { Department of Colloid Chemistry, Max-Planck Institute } \\
\text { of Colloids and Interfaces, Golm, Germany }\end{array}$ & Water-soluble polymers, polymer modification \\
\hline 2003 & $\begin{array}{l}\text { Department of Polymer Engineering, Faculty of } \\
\text { Applied Natural Sciences, University of Bayreuth, } \\
\text { Germany }\end{array}$ & Block copolymers, polymer blends \\
\hline 2004 & $\begin{array}{l}\text { Department of Technology of Elastomers and Chemical } \\
\text { Fibres, Technical University of Szczecin, Poland }\end{array}$ & $\begin{array}{l}\text { Polycondensation, hydrogels, biodegradable } \\
\text { polyesters }\end{array}$ \\
\hline 2004-2010 & $\begin{array}{l}\text { Institute of Macromolecular Chemistry, Academy } \\
\text { of Sciences of the Czech Republic, Prague, Czech } \\
\text { Republic }\end{array}$ & $\begin{array}{l}\text { Amphiphilic block copolymers, controlled radical } \\
\text { polymerization, click chemistry }\end{array}$ \\
\hline 2005-2007 & $\begin{array}{l}\text { Department of Polymer Chemistry, Vilnius University, } \\
\text { Vilnius, Lithuania }\end{array}$ & $\begin{array}{l}\text { Controlled radical polymerization, click } \\
\text { chemistry, comb copolymers, molecular brushes }\end{array}$ \\
\hline 2009 & Polymerics GmBH, Berlin, Germany & $\begin{array}{l}\text { Suspension polymerization, polymeric adsorbents, } \\
\text { surface modification }\end{array}$ \\
\hline 2010 & $\begin{array}{l}\text { Fundamentals of Advanced Materials Group, Faculty } \\
\text { of Aerospace Engineering, Delft University of } \\
\text { Technology, Delft, The Netherlands }\end{array}$ & $\begin{array}{l}\text { High performance engineering plastics from green } \\
\text { building blocks, fibres, self-healing polymers, } \\
\text { macromolecular engineering }\end{array}$ \\
\hline
\end{tabular}

Upon receiving a second Marie Curie Fellowship within the MCRTN-SOCON, he moved to the Department of Polymer Chemistry at Vilnius University. This 6th European Framework Programme funded 13 teams in 9 countries within 4-year project, which was very productive and successful in terms of output and cooperation. For more information about MCRTNSOCON the reader is referred to a special issue in Adv Colloid Interface Sci 155: 1-58, exclusively devoted to SOCON consortium. The aim of the MCRTNSOCON was to understand the link between surface properties, bulk properties, films, and macroscopic colloidal systems. The particular focus was on mixed surfactant systems, surfactant-polymer systems, and on comb polymers (Stubenrauch 2010). The expertise of the Vilnius group focuses on the synthesis of novel polymers characterized by controlled composition and charge density including meth(acrylate) comb copolymers, molecular brushes and poly(ethylene glycol)grafted chitosan. The research and educational program including goals and objectives, complementary skills and research management were set in a personal career development plan individually tailored for each Early Stage Researcher (ESR) or Experienced Researcher (ER) fellow of the SOCON network. The experience that Dr. Gromadzki gained during his
Marie Curie Fellowships and career mobility (Table 1) was extraordinarily helpful for his professional life as well as for his personal development. Marie Curie once said- "After all, science is essentially international, and it is only through lack of the historical sense that national qualities have been attributed to it". Indeed, SOCON network was a prominent example of the international effort for advancement of science and cross-border collaboration.

Open Access This article is distributed under the terms of the Creative Commons Attribution Noncommercial License which permits any noncommercial use, distribution, and reproduction in any medium, provided the original author(s) and source are credited.

\section{References}

Braunecker WA, Matyjaszewski K (2007) Controlled/living radical polymerization: features, developments, and perspectives. Prog Polym Sci 32:93-146

Claesson PM, Makuska R, Varga I, Meszaros R, Titmuss S, Linse P, Pedersen JS, Stubenrauch C (2010) Bottle-brush polymers: adsorption at surfaces and interactions with surfactants. Adv Colloid Interface Sci 155:50-57

Gromadzki D, Lokaj J, Cernoch P, Nallet F, Diat O, Stepanek P (2008a) Morphology of polystyrene-block-poly(styreneco-acrylonitrile) and polystyrene-block-poly(styrene-co- 
acrylonitrile-co-5-vinyltetrazole) diblock copolymers prepared by nitroxode-mediated radical polymerization and "click" chemistry. Eur Polym J 44:189-199 (Hot article)

Gromadzki D, Makuska R, Netopilík M, Holler P, Lokaj J, Janata M, Stepanek P (2008b) Comb copolymers of polystyrene-poly(tert-butyl (meth)acrylate) prepared by combination of nitroxide-mediated polymerization and photoinduced iniferter technique. Eur Polym J 44:59-71 (Hot article)

Gromadzki D, Jigounov A, Stepanek P, Makuska R (2010) Synthesis of thermally responsive cylindrical molecular brushes via a combination of nitroxide-mediated radical polymerization and "grafting onto" strategy. Eur Polym J 46:804-813 (Invitation from ELSEVIER for SciTopics)

Holden G, Kricheldorf HR, Quirk R (eds) (2004) Thermoplastic elastomers, 3rd edn. Hanser Publishers, Munich

Iha RK, Wooley KL, Nyström AM, Burke DJ, Kade MJ, Hawker CJ (2009) Applications of orthogonal "click" chemistries in the synthesis of functional soft materials. Chem Rev 109:5620-5686

Kang Y, Walish JJ, Gorishnyy T, Thomass EL (2007) Broadwavelength-range chemically tunable block-copolymer photonic gels. Nat Mater 6:957-960

Kataoka K, Kwon GS, Yokoyama M, Okano T, Sakurai Y (1993) Block copolymer micelles as vehicles for drug delivery. J Control Release 24:119-132

Kolb HC, Finn MG, Sharpless KB (2001) Click chemistry: diverse chemical function from a few good reactions. Angew Chem Int Ed 40:2004-2021
Krivorotova T, Makuska R, Naderi A, Claesson PM, Dedinaite A (2010a) Synthesis and interfacial properties of novel cationic polyelectrolytes with brush-on-brush structure of poly(ethylene oxide) side chains. Eur Polym J 46:171-180

Krivorotova T, Vareikis A, Gromadzki D, Netopilík M, Makuska R (2010b) Conventional free-radical and RAFT copolymerization of poly(ethylene oxide) containing macromonomers. Eur Polym J 46:546-556

Kulbokaite R, Ciuta G, Netopilík M, Makuska R (2009) NPEG'ylation of chitosan via "click chemistry" reactions. React Funct Polym 69:771-778 (Hot article)

Lynd NA, Meuler AJ, Hillmyer MA (2008) Polydispersity and block copolymer self-assembly. Prog Polym Sci 33: 875-893

Ruzette AV, Leibler L (2005) Block copolymers in tomorrow's plastics. Nat Mater 4:19-31

Stubenrauch C (2010) Foreword of the SOCON co-ordinator. Adv Colloid Interface Sci 155:1-2

Xia Y, Whitesides GM (1998) Soft Lithography. Angew Chem Int Ed 37:550-575

\section{Weblinks}

Marie Curie Fellows Association, http://mcfa.eu/

Marie Curie Research and Training Network Self-Organization under Confinement SOCON

http://www.mcrtn-socon.org/ 